\title{
Dithienonaphthalene-Based Non-fullerene Acceptors With Different Bandgaps for Organic Solar Cells
}

\author{
Meiqi Zhang ${ }^{1,2}$, Yunlong $\mathrm{Ma}^{1}$ and Qingdong Zheng ${ }^{1 *}$ \\ ${ }^{1}$ State Key Laboratory of Structural Chemistry, Fujian Institute of Research on the Structure of Matter, Chinese Academy of \\ Sciences, Fuzhou, China, ${ }^{2}$ University of Chinese Academy of Sciences, Beijing, China
}

OPEN ACCESS

Edited by:

Chuanlang Zhan

Institute of Chemistry (CAS), China

Reviewed by:

Chaohua Cui,

Soochow University, China

Jianhua Huang,

Huaqiao University, China

*Correspondence:

Qingdong Zheng

qingdongzheng@fjirsm.ac.cn

Specialty section:

This article was submitted to

Organic Chemistry,

a section of the journal

Frontiers in Chemistry

Received: 07 July 2018

Accepted: 30 August 2018

Published: 24 September 2018

Citation:

Zhang M, Ma Y and Zheng Q (2018) Dithienonaphthalene-Based Non-fullerene Acceptors With Different Bandgaps for Organic Solar Cells.

Front. Chem. 6:427.

doi: $10.3389 /$ fchem.2018.00427
Compared to the traditional fullerene derivatives, non-fullerene acceptors show more tunable absorption bands as well as adjustable energy levels which are favorable for further PCE enhancement of organic solar cells. In order to enhance light-harvesting property of dithienonaphthalene (DTN)-based acceptors, we designed and synthesized two novel non-fullerene acceptors (DTNIF and DTNSF) based on a ladder-type DTN donor core flanked with two different acceptor units. In combination with a benchmark wide bandgap copolymer (PBDB-T), the best performance device based on DTNIF displayed a high PCE of $8.73 \%$ with a short-circuit current $\left(\mathrm{J}_{\mathrm{sc}}\right)$ of $13.26 \mathrm{~mA} \mathrm{~cm}^{-2}$ and a large fill factor (FF) of $72.77 \%$. With a reduced bandgap of DTNSF, the corresponding best performance device showed an increased $J_{\mathrm{Sc}}$ of $14.49 \mathrm{~mA} \mathrm{~cm}-2$ although only a moderate PCE of $7.15 \%$ was achieved. These findings offer a molecular design strategy to control the bandgap of DTN-based non-fullerene acceptors with improved light-harvesting.

Keywords: organic solar cell, non-fullerene, ladder-type structure, power conversion efficiency, bandgap

\section{INTRODUCTION}

Organic solar cells (OSCs) have attracted increasing attention over the past decade due to their light-weight, mechanical flexibility, and potential low-cost (Facchetti, 2011; Liu et al., 2014; Rong et al., 2015). Bulk heterojunction (BHJ) OSCs featuring with an active layer of an electron acceptor material blended with an electron donor material, are widely used (Wu et al., 2011; Chen et al., 2013; Wang et al., 2014; Xu et al., 2015). In the early years' research on OSCs, fullerene derivatives, such as [6,6]-phenyl-C71-butyric acid methyl ester $\left(\mathrm{PC}_{71} \mathrm{BM}\right)$ and [6,6]-phenyl-C61-butyric acid methyl ester $\left(\mathrm{PC}_{61} \mathrm{BM}\right)$ have been used as the dominant electron acceptors due to their high electron mobilities and unique phase separation property when blended with rod-like donor materials (You et al., 2013; Ma et al., 2016). Although power conversion efficiencies (PCEs) of fullerene-based OSCs have surpassed 10\% in single-junction OSCs (Liu et al., 2014; Chen et al., 2015; He et al., 2015; Zhang et al., 2015), the poor absorption in the visible region and the limited tunability in energy levels of the fullerene derivatives prevent a further PCE improvement of fullerene-based OSCs (Zhan et al., 2011). To break these limitations, emerging efforts have thus been devoted to designing non-fullerene acceptors which could have broader absorption, more adjustable energy levels and structural flexibility in comparison with the fullerene derivatives (Li et al., 2015; Lin et al., 2015; Nielsen et al., 2015; Liu et al., 2016, 2018; Qin et al., 2016; Zhang et al., 2016; Tang et al., 2017; Shen et al., 2018). Among the non-fullerene acceptors, small molecules with 
acceptor-donor-acceptor (A-D-A) configuration are popular in organic photovoltaic field because the HOMO and LUMO energy levels of A-D-A type molecules can be separately tuned by selecting suitable donor cores and acceptor terminals (Lin et al., 2015; Wu et al., 2015; Zhao et al., 2017). Using ladder-type angular-shaped dithienonaphthalene (DTN) as the donor unit and 2-(3-oxo-2,3-dihydro-1H-inden-1-ylidene)malononitrile (INCN) as the strong electron-withdrawing unit, we reported an A-D-A type non-fullerene acceptor (DTNIC8), recently, which exhibited a bandgap of $1.73 \mathrm{eV}$ and a decent PCE of 9.03\% (Ma et al., 2017b). In order to obtain DTN-based nonfullerene acceptors with an up-shifted LUMO energy level, we further used 5-(benzo[c][1,2,5]thiadiazol-4-ylmethylene)-3ethyl-2-thioxothiazolidin-4-one as the weak electron-deficient group (Ma et al., 2017a). The resulting non-fullerene acceptor (DTNR) exhibited a similar bandgap of $1.72 \mathrm{eV}$ but a much high-lying LUMO energy level of $-3.75 \mathrm{eV}$ which is beneficial for achieving a large $V_{\text {oc }}$ for the corresponding PSC. Both the DTN-based acceptors showed relatively wide bandgaps with intense absorption bands in the range of 500-750 nm (Ma et al., $2017 a, b)$. In order to improve the PCEs of OSCs based on wide bandgap donor materials, the bandgaps of non-fullerene acceptors based on DTN should be reduced further. For the A-D-A type non-fullerene acceptors, their bandgaps can be reduced by using stronger electron withdrawing groups as terminals (Zhao et al., 2017) and by extending $\pi$-conjugation length of the molecular backbone (Dai et al., 2017).

In this context, two novel DTN-based non-fullerene acceptors, DTNIF and DTNSF, were designed and synthesized by using a stronger electron withdrawing group of 2-(6-fluoro3-oxo-2,3-dihydro-1H-inden-1-ylidene)malononitrile (INCNF), or by inserting two additional thiophene bridges in molecular backbone (shown in Figure 1). Inverted OSCs were fabricated by blending a typical wide bandgap copolymer (PBDB-T in Figure 1) with the DTN-based non-fullerene acceptors. The PBDB-T:DTNIF-based devices exhibited a PCE of $8.73 \%$ with a high FF of $72.77 \%$, and a short circuit current $\left(J_{\mathrm{sc}}\right)$ of $13.26 \mathrm{~mA}$ $\mathrm{cm}^{-2}$. However, the PBDB-T:DTNSF-based devices showed a moderate PCE of $7.15 \%$ with an increased $J_{\mathrm{sc}}$ of $14.49 \mathrm{~mA} \mathrm{~cm}^{-2}$ and a low FF of $54.62 \%$. Moreover, we also studied effects of the terminal units on the bandgap, energy level, and charge transporting property of the DTN-based non-fullerene acceptors.

\section{RESULTS AND DISCUSSION}

\section{Synthesis and Characterization}

The synthetic routes of DTNIF and DTNSF are shown in Scheme 1 and the synthetic details are described in the Experimental section. Compounds $\mathbf{1}$ and $\mathbf{2}$ were synthesized according to our earlier published methods (Ma et al., 2013, 2017b).

Compound 3 was obtained in $96 \%$ yield by the Stille coupling reaction between Compound 2 and 5-bromothiophene2-carbaldehyde using $\mathrm{Pd}\left(\mathrm{PPh}_{3}\right)_{4}$ as the catalyst. A Knoevenagel condensation reaction between Compound $\mathbf{3}$ and INCNF afforded DTNSF in $46 \%$ yield. DTNIF was synthesized in $60 \%$ yield by using the same condensation reaction between
Compound 1 and INCNF. The chemical structures of DTNIF and DTNSF were determined by using ${ }^{1} \mathrm{H}$ NMR and high-resolution mass spectrometry. The purity of the acceptors was verified further by elemental analysis. All non-fullerene materials are soluble at room temperature in the traditional organic solvents, such as $\mathrm{CH}_{2} \mathrm{Cl}_{2}$, chlorobenzene, and $\mathrm{CHCl}_{3}$ etc.

\section{Optical and Electrochemical Properties}

The absorption properties of DTNIF and DTNSF were investigated in $\mathrm{CHCl}_{3}$ solution as well as in thin film. The obtained linear absorption spectra are shown in Figure $\mathbf{2}$ and the specific optical data are shown in Table 1.

In chloroform solution, DTNIF displayed a strong absorption band in the wavelength region of $500-700 \mathrm{~nm}$ with a clear shoulder peak at $600 \mathrm{~nm}$ which can be attributed to the intramolecular charge transfer from the electron donating core to the electron withdrawing terminals. Compared to DTNIF, DTNSF showed a red-shifted absorption band in the wavelength region of $520-780 \mathrm{~nm}$ which can be ascribed to its extended conjugation with two additional thiophene bridges. The maximum extinction coefficient of DTNIF $\left(1.8 \times 10^{5} \mathrm{M}^{-1} \mathrm{~cm}^{-1}\right.$ at $637 \mathrm{~nm})$ was higher than that of DTNSF $\left(1.4 \times 10^{5} \mathrm{M}^{-1}\right.$ $\mathrm{cm}^{-1}$ at $682 \mathrm{~nm}$ ). From solution to thin film, both the nonfullerene acceptors showed broader and red-shifted absorptions. The optical bandgaps estimated from their absorption edges were $1.63 \mathrm{eV}$ and $1.47 \mathrm{eV}$ for DTNIF and DTNSF, respectively, both of which are lower than the bandgap of DTNIC8 $(1.73 \mathrm{eV}$ in Table 1). With the standard A-D-A configuration in the molecular backbone, DTNIF exhibits a deep HOMO energy level of $-5.82 \mathrm{eV}$. However, with the insertion of two additional thiophene units in the A-D-A backbone, the HOMO energy level of DTNSF increases to $-5.52 \mathrm{eV}$ together with a significant reduced bandgap of $1.47 \mathrm{eV}$ which is mainly attributed to its extended $\pi$-conjugation in comparison with DTNIF. As shown in Figure 2B, DTNSF in thin film exhibits a more complementary absorption spectrum with PBDB-T in comparison that with DTNIF, suggesting a possible enhanced $J_{\text {sc }}$ value for the DTNSFbased OSC.

The electrochemical properties of the non-fullerene acceptors were tested by electrochemical cyclic voltammetry (CV). Here, ferrocene was used as an internal reference, which has a HOMO level of $-4.80 \mathrm{eV}$. The cyclic voltammograms are shown in Figure $\mathbf{3 A}$ and the corresponding data are listed in Table $\mathbf{1 .}$ According to their onset potentials, the HOMO/LUMO energy levels of DTNIF and DTNSF were calculated to be $-5.82 /-3.92$ and $-5.52 /-4.00 \mathrm{eV}$, respectively. $\mathrm{PBDB}-\mathrm{T}$ has $\mathrm{HOMO}$ and LUMO energy levels of -5.33 and $-2.92 \mathrm{eV}$, respectively, which energetically matched with those of the acceptors (Figure 3B).

\section{Photoluminescence}

In order to know the exciton dissociation as well as the charge transfer behaviors of donor/acceptor blends, photoluminescence (PL) quenching experiments were carried out and the results were shown in Figure 4. We selected $665 \mathrm{~nm}$ and $750 \mathrm{~nm}$ as the excitation wavelengths to respectively excite DTNIF and DTNSF in either pure or blend films. The donor/acceptor blend ratios were fixed at 1:1 by mol. As shown in Figures $4 \mathrm{~A}, \mathrm{C}$, the 

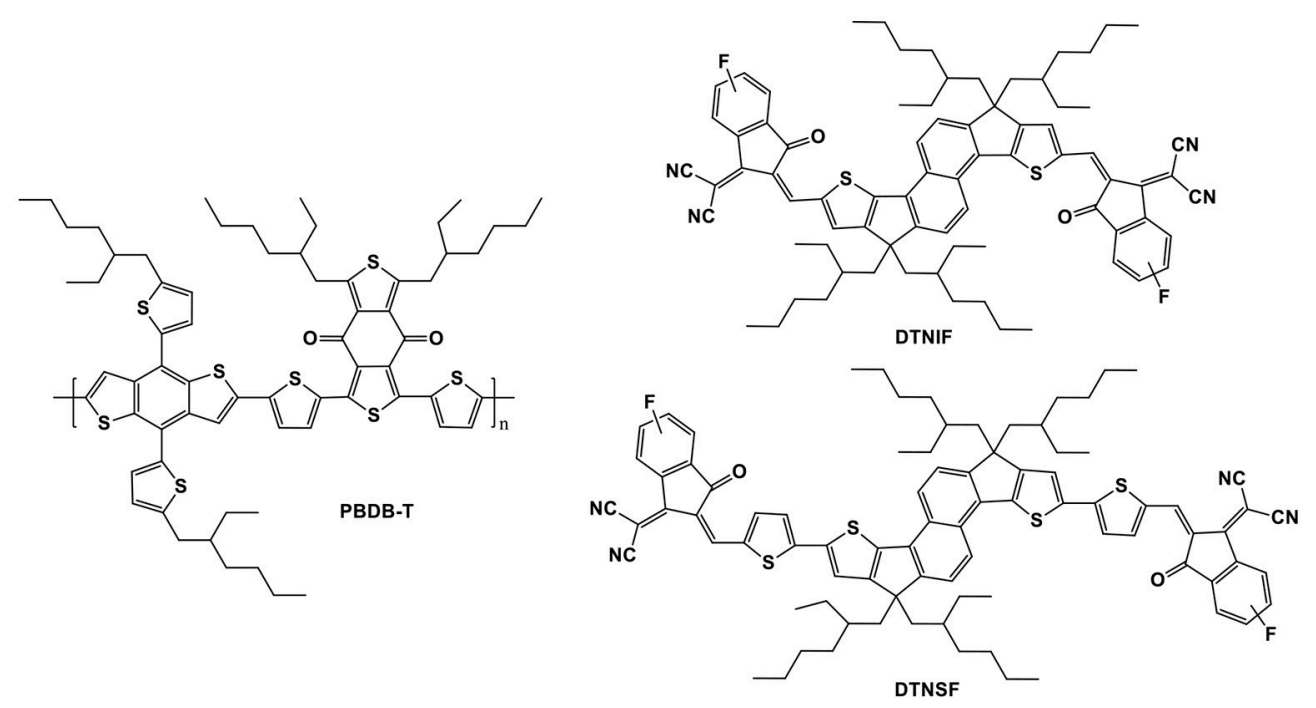

FIGURE 1 | Chemical structures of PBDB-T and the target non-fullerene acceptors.
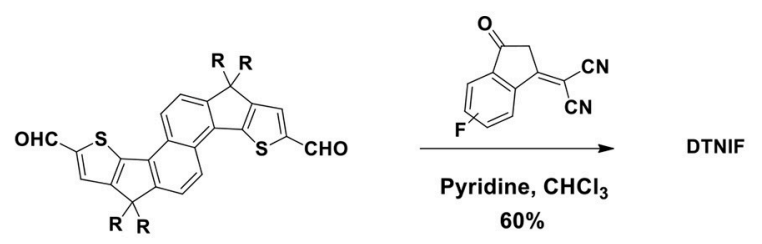

1

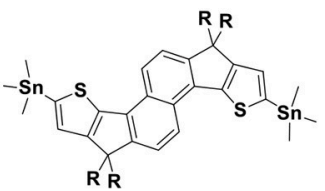

2

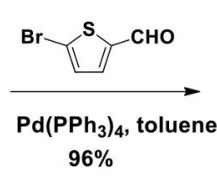

$96 \%$

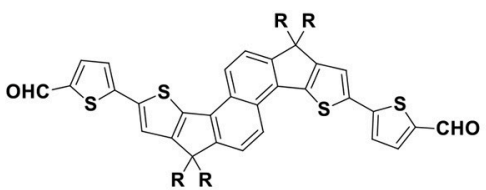

3

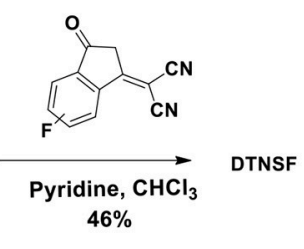

R=2-ethylhexyl

SCHEME 1 | Synthetic routes of the non-fullerene acceptors.
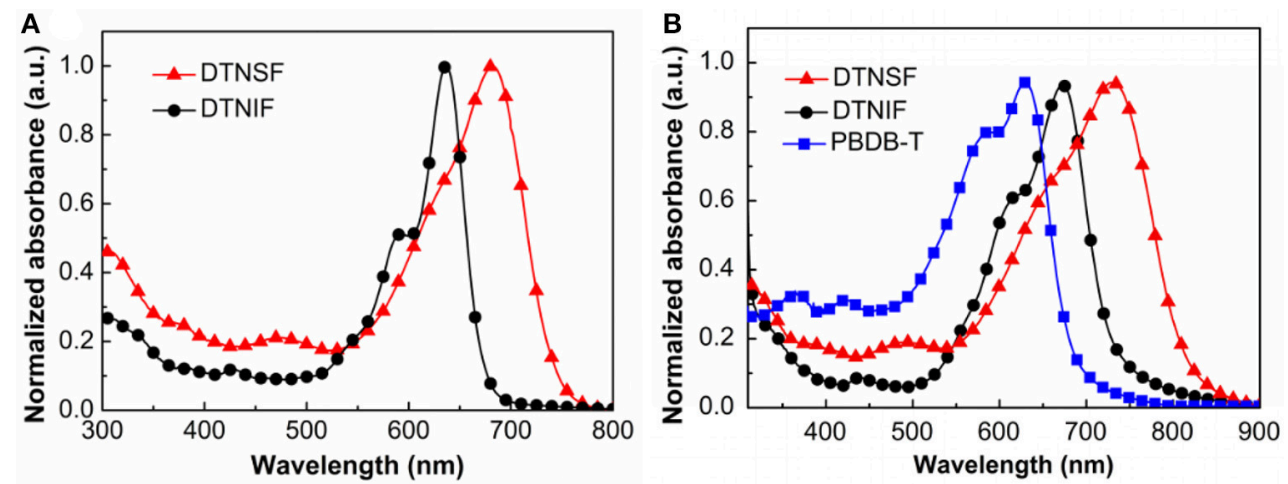

FIGURE 2 | (A) Normalized UV-Vis absorption spectra of DTNIF and DTNSF in $\mathrm{CHCl}_{3}$. (B) Normalized UV-Vis absorption spectra of DTNIF, DTNSF, and PBDB-T in thin film. 
TABLE 1 | Optical and electrochemical properties of DTNIF and DTNSF.

\begin{tabular}{|c|c|c|c|c|c|c|c|}
\hline Molecules & $\varepsilon\left[10^{5} \mathrm{M}^{-1} \mathrm{~cm}^{-1}\right]$ & $\lambda_{\max }^{\text {solution }}[\mathrm{nm}]$ & $\lambda_{\max }^{\text {film }}[n m]$ & $\mathrm{E}_{\mathrm{g}}^{\mathrm{opt}}[\mathrm{eV}]^{\mathrm{a}}$ & Hомо $[\mathrm{eV}]^{\mathrm{b}}$ & LUMO $[\mathrm{eV}]^{\mathrm{c}}$ & References \\
\hline DTNIF & 1.8 & 636 & 672 & 1.63 & -5.82 & -3.92 & This work \\
\hline DTNSF & 1.4 & 682 & 731 & 1.47 & -5.52 & -4.00 & This work \\
\hline
\end{tabular}

${ }^{a}$ Estimated from the onset of the absorption spectra of thin films; ${ }^{b} E_{H O M O}=-\left(\varphi_{0 x}+4.82\right) \mathrm{eV} ;{ }^{c} E_{L U M O}=-\left(\varphi_{\text {red }}+4.82\right) \mathrm{eV}$.
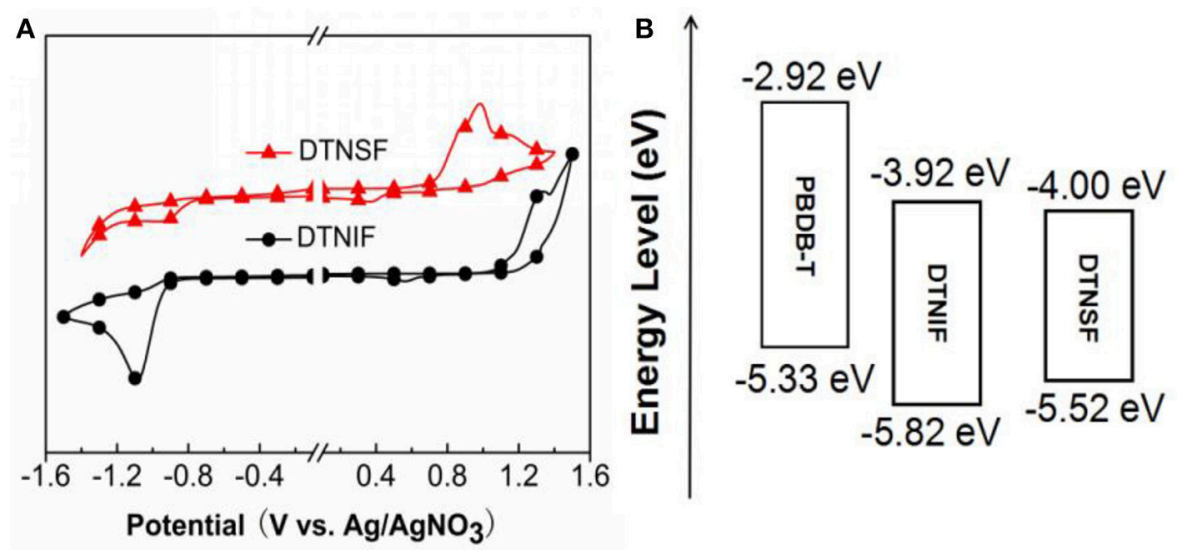

FIGURE 3 | (A) Cyclic voltammograms of DTNIF and DTNSF. (B) Estimated energy level diagram of DTNIF, DTNSF, and PBDB-T.

strong emission of DTNIF at $700 \mathrm{~nm}$ and $760 \mathrm{~nm}$ (DINSF at $825 \mathrm{~nm}$ ) in the blend film apparently quenched when compared to that in the pure film, demonstrating the efficient hole transfer from both the acceptors to PBDB-T (donor). As for the PL emission of PBDB-T (shown in Figures 4B,D), the PL intensities of PBDB-T:DTNIF and PBDB-T:DTNSF blend films decreased significantly in comparison with those of the pure PBDB-T film when excited at 570 and $580 \mathrm{~nm}$, respectively. It suggested that there is efficient electron transfer from the PBDB-T donor to both the acceptors. These results demonstrated that both the non-fullerene acceptors and the polymer donor contribute to the photocurrent generation of the OSCs.

\section{Photovoltaic Performance}

PBDB-T is a wide-bandgap polymer donor which has a strong absorption band in the wavelength range from 500 to $700 \mathrm{~nm}$. The absorption bands of our non-fullerene acceptors generally match the absorption band of PBDB-T. Thus, we chose PBDB-T as donor to fabricate OSCs with an inverted device structure: indium tin oxide (ITO)/ $\mathrm{ZnO} /$ donor:acceptor $/ \mathrm{MoO}_{3} / \mathrm{Ag}$. The active layers were spin-coated by using PBDBT:acceptor ( $\mathrm{w} / \mathrm{w}, 1: 1)$ blend solution in chlorobenzene (18 $\mathrm{mg} / \mathrm{mL}$ ) without any additives and post-treatments. The $J-V$ curves of the best performance devices are shown in Figure 5A and detailed device parameters are summarized in Table 2.

Under simulated AM 1.5 G, $100 \mathrm{~mW} \mathrm{~cm}^{-2}$ illumination and the optimal device fabrication condition, the best performance OSC based on PBDB-T:DTNIF showed a PCE of $8.73 \%$ with a $V_{\text {oc }}$ of $0.90 \mathrm{~V}$, a $J_{\text {sc }}$ of $13.26 \mathrm{~mA} \mathrm{~cm}$ cm $^{-2}$ and a $\mathrm{FF}$ of $72.77 \%$. Nevertheless, the best performance DTNSF-based device exhibited a PCE of $7.15 \%$ with a $V_{\text {oc }}$ of $0.92 \mathrm{~V}$ and a lower FF of $54.62 \%$. The lower FF was mainly resulted from the lower and less balanced hole and electron mobilities for the PBDBT:DTNSF active layer. However, the $J_{\mathrm{sc}}$ of $14.49 \mathrm{~mA} \mathrm{~cm}^{-2}$ for the DTNSF-based device is larger than the PBDB-T:DTNIFbased counterpart owing to the red-shifted absorption of DTNSF. We noticed that the DTNSF-based device showed a slightly higher $V_{\text {oc }}$ than the DTNIF-based device despite the fact that DTNIF possesses a higher LUMO level than DTNSF. Besides the energy gap (between HOMO of the donor and LUMO of the acceptor) which can affect the $V_{\text {oc }}$ of corresponding device, other factors, such as recombination rate, reverse saturation current, carrier density, defect states and crystallinity, and charge-transfer states could also play an important role in influencing the $V_{\text {oc }}$ (Elumalai and Uddin, 2016). Therefore, it is reasonable that the DTNIF-based device exhibited a relatively lower $V_{\text {oc }}$ of $0.90 \mathrm{~V}$.

As shown in Figure 5B, external quantum efficiency (EQE) spectra of the best performance devices were measured to ensure the accuracy of the PCE measurements. The device based on DTNIF has higher EQE values in the wavelength range of 300$750 \mathrm{~nm}$ with a maximum value of $78 \%$ at $660 \mathrm{~nm}$. In contrast, the EQE spectrum edge of the best performance DTNSF-based device extended to $850 \mathrm{~nm}$, which agrees with the absorption spectrum of the DTNSF blend film. The $J_{\mathrm{sc}}$ values obtained by integrating the EQE data with the solar spectrum (AM $1.5 \mathrm{G}$ ) were 13.26 and $14.21 \mathrm{~mA} \mathrm{~cm}{ }^{-2}$ for DTNIF and DTNSF, 

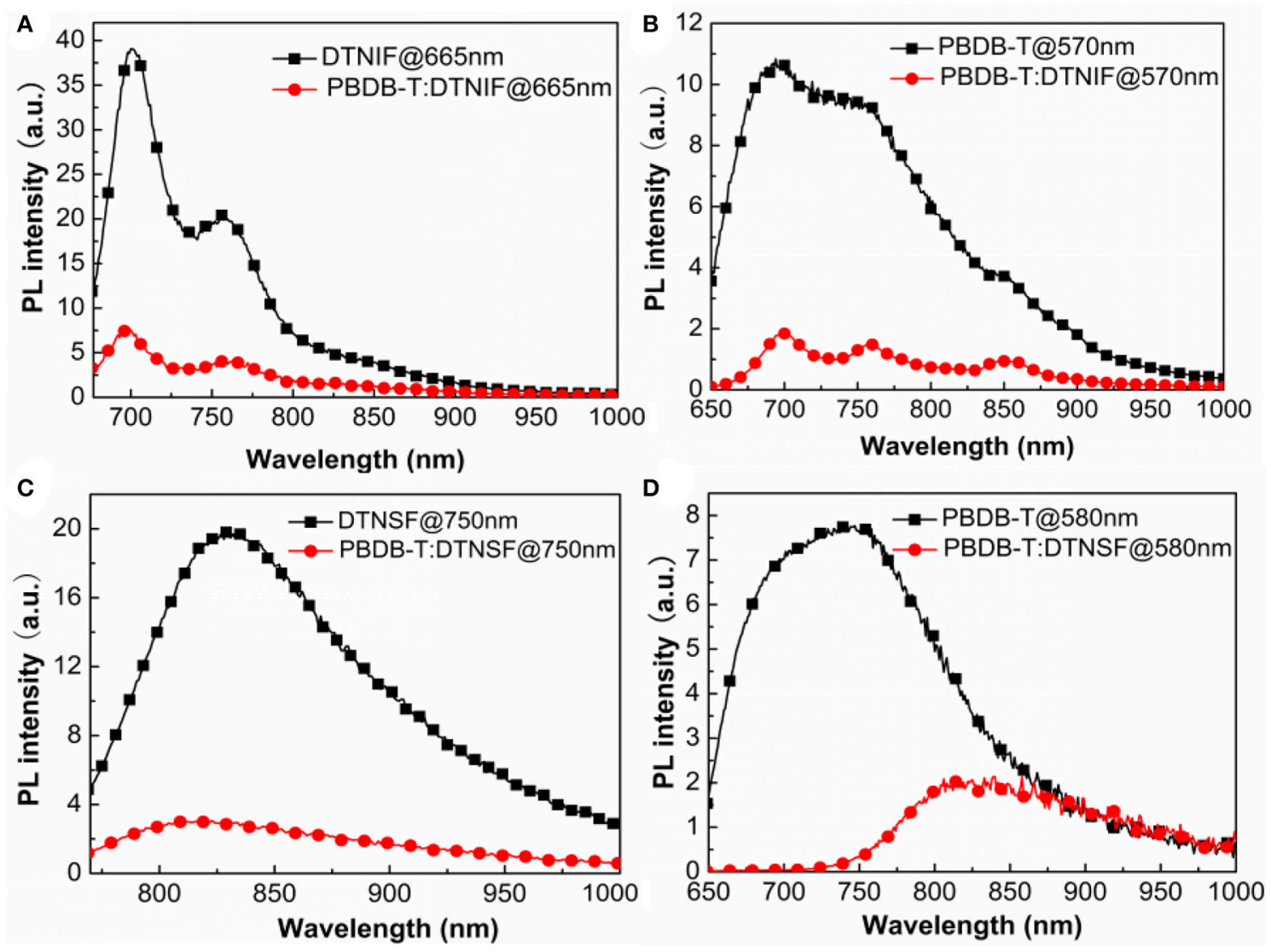

FIGURE 4 | Fluorescence quenching experiments of PBDB-T:DTNIF (A,B) and PBDB-T:DTNSF (C,D) excited mainly by the acceptor $(\mathbf{A}, \mathbf{C})$ and the donor $(\mathbf{B}, \mathbf{D})$.
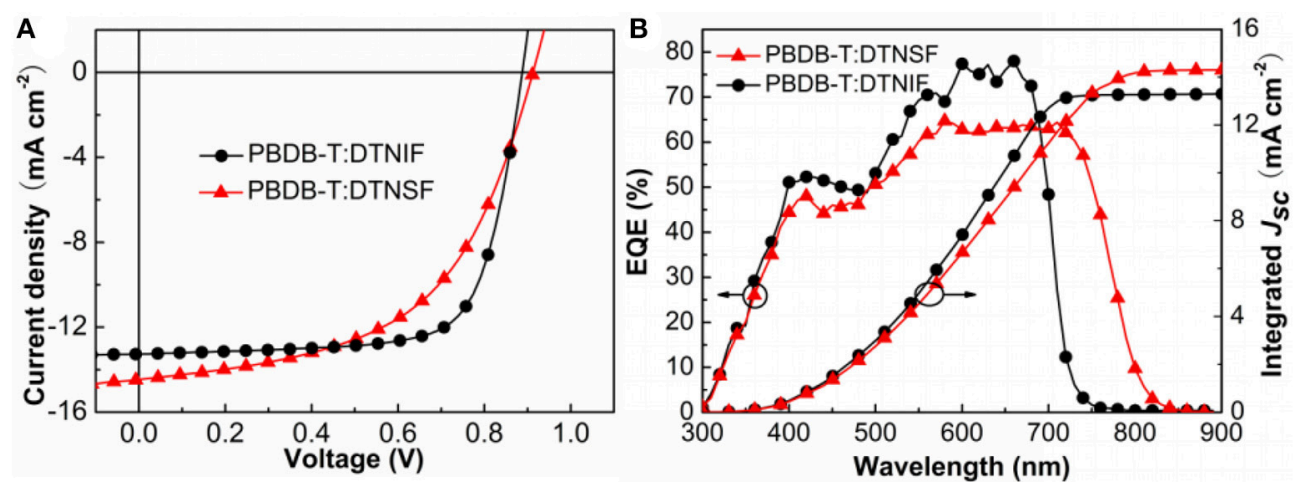

FIGURE 5 | (A) J-V characteristics of the non-fullerene OSCs. (B) EQE and the corresponding integrated $J_{\text {sc }}$ curves for the OSCs.

respectively. The integrated values are in consistent with those from the $J$ - $V$ measurement within $2 \%$ error.

\section{Film Morphology Analysis}

Tapping-mode atomic force microscopy (AFM) was used to characterize the morphology of active layer that has an important influence on the performance of OSCs. The film samples for AFM analysis were prepared in identical fashion to those prepared for device fabrication in which the donor/acceptor blend ratios were fixed at 1:1 by mol. The obtained AFM images were presented in Figure 6. The AFM height images of the DTNIF and DTNSF-based blend films showed similar and apparently fibrillar structures (Figures 6A,B). However, the DTNSF-based blend shows smoother root-mean-square (RMS) roughness $\left(\mathrm{R}_{\mathrm{q}}\right)$ than the DTNIF-based blend. Compared to PBDB-T:DTNIF film with a $\mathrm{R}_{\mathrm{q}}$ of $3.25 \mathrm{~nm}$, the RMS roughness of PBDB-T:DTNSF film 
decreased to $2.09 \mathrm{~nm}$ which could be attributed to the smaller intramolecular twisted angel and greater coplanarity of DTNSF. As shown in the phase images (Figures 6C,D), fibrillar structure can also be observed in both the blend films. In comparison with PBDB-T:DTNSF blend film, PBDB-T:DTNIF film revealed fibrillar structures with larger sizes which will be favorable for efficient charge transport in the DTNIF-based devices as confirmed by their higher hole and electron mobilities.

As mentioned above, the optimal morphology can enhance charge transport efficiency that will further affect the $J_{\mathrm{sc}}$ and FF of OSCs. We measured the electron $\left(\mu_{e}\right)$ and hole $\left(\mu_{h}\right)$ mobilities using the space charge limited current (SCLC) method with the device structures of ITO/ZnO/PBDB-T:acceptor/Ca/Al and ITO/PEDOT:PSS/PBDB-T:acceptor/Au, respectively. For both the hole- and electron-only devices, the donor/acceptor ratios for are fixed at $1: 1$ by mol. The $J-V$ characteristics of the hole-only and electron-only devices are shown in Figure 7 and the mobility data are shown in Table 3. The $\mu_{e}$ and $\mu_{h}$ for the PBDB-T:DTNIF blend film were calculated to be $1.79 \times 10^{-5}$ and $1.87 \times 10^{-5} \mathrm{~cm}^{2}$

TABLE 2 | Photovoltaic properties of OSCs (under AM 1.5 G, $100 \mathrm{~mW} \mathrm{~cm}^{-2}$ ).

\begin{tabular}{lcccc}
\hline Active layer & $\boldsymbol{V}_{\mathbf{o c}}(\mathbf{V})$ & $\boldsymbol{J}_{\mathbf{s c}}\left(\mathbf{m A ~ c m} \mathbf{~ m}^{-\mathbf{2}}\right)$ & $\mathbf{F F}(\%)$ & PCE (\%) \\
\hline PBDB-T:DTNIF & 0.90 & 13.26 & 72.77 & $8.73(8.65 \pm 0.23)$ \\
PBDB-T:DTNSF & 0.92 & 14.49 & 54.62 & $7.15(6.94 \pm 0.20)$
\end{tabular}

$\mathrm{V}^{-1} \mathrm{~s}^{-1}$, respectively, which far exceeded those for the PBDBT:DTNSF film $\left(\mu_{e}=6.70 \times 10^{-6}\right.$ and $\mu_{h}=1.35 \times 10^{-5} \mathrm{~cm}^{2}$ $\left.\mathrm{V}^{-1} \mathrm{~s}^{-1}\right)$. More balanced $\mu_{h} / \mu_{e}$ ratio of 1.04 was observed for the PBDB-T:DTNIF blend film when compared to a larger $\mu_{h} / \mu_{e}$ ratio of 2.01 for the PBDB-T:DTNSF blend. Thus, the higher and more balanced hole and electron mobilities of the PBDBT:DTNIF blend can explain the higher FF of the resulting solar cell.

\section{CONCLUSIONS}

In summary, we have developed two novel non-fullerene acceptors, DTNIF and DTNSF, with different bandgaps. The introduction of $\mathrm{F}$ atom into the terminal group leads to a slightly narrow bandgap and a red-shifted absorption in the 500-750 nm region. To achieve a more complementary spectrum of nonfullerene acceptor with wide bandgap donor materials, such as PBDB-T, we further introduced two thiophenes as bridge units which lead to a more planar molecular configuration with an extended conjugation. Without any additive and post-treatment, the best performance DTNIF-based device exhibited a PCE of $8.73 \%$ with $V_{\text {oc }}$ of $0.90 \mathrm{~V}$, FF of $72.77 \%$ and $J_{\text {sc }}$ of $13.26 \mathrm{~mA} \mathrm{~cm}^{-2}$. The best performance device based on DTNSF afforded an enhanced $J_{\mathrm{sc}}$ of $14.49 \mathrm{~mA} \mathrm{~cm}{ }^{-2}$ although only a moderate PCE of $7.15 \%$ was obtained due to the decreased and unbalanced hole and electron mobilities of the DTNSF-based active layer. It should be noted that the device performance of DTNIF-based
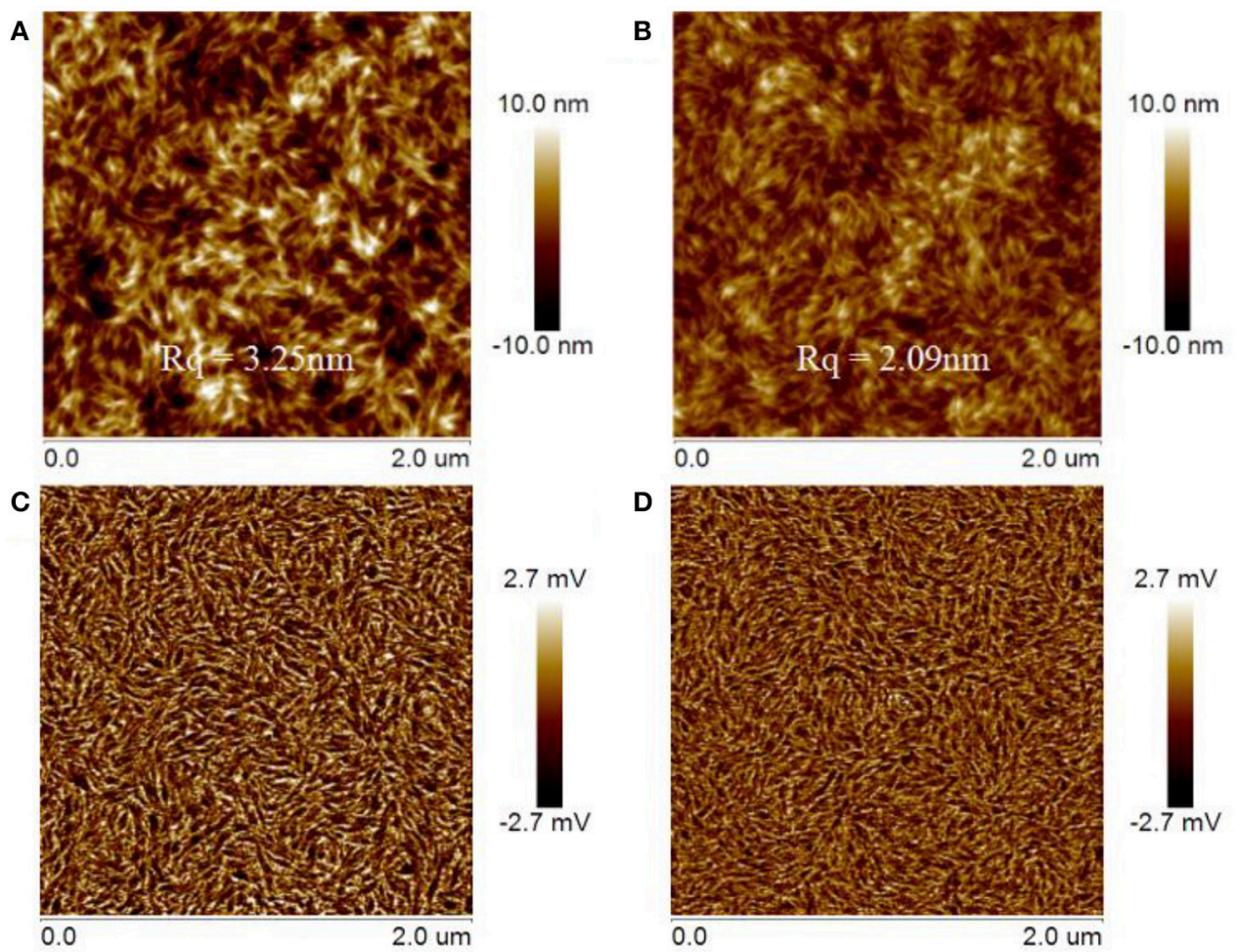

FIGURE 6 | Tapping-mode AFM topography images (A,B) and phase (C,D) images of the PBDB-T:DTNIF (A,C) and PBDB-T:DTNSF (B,D) films. 

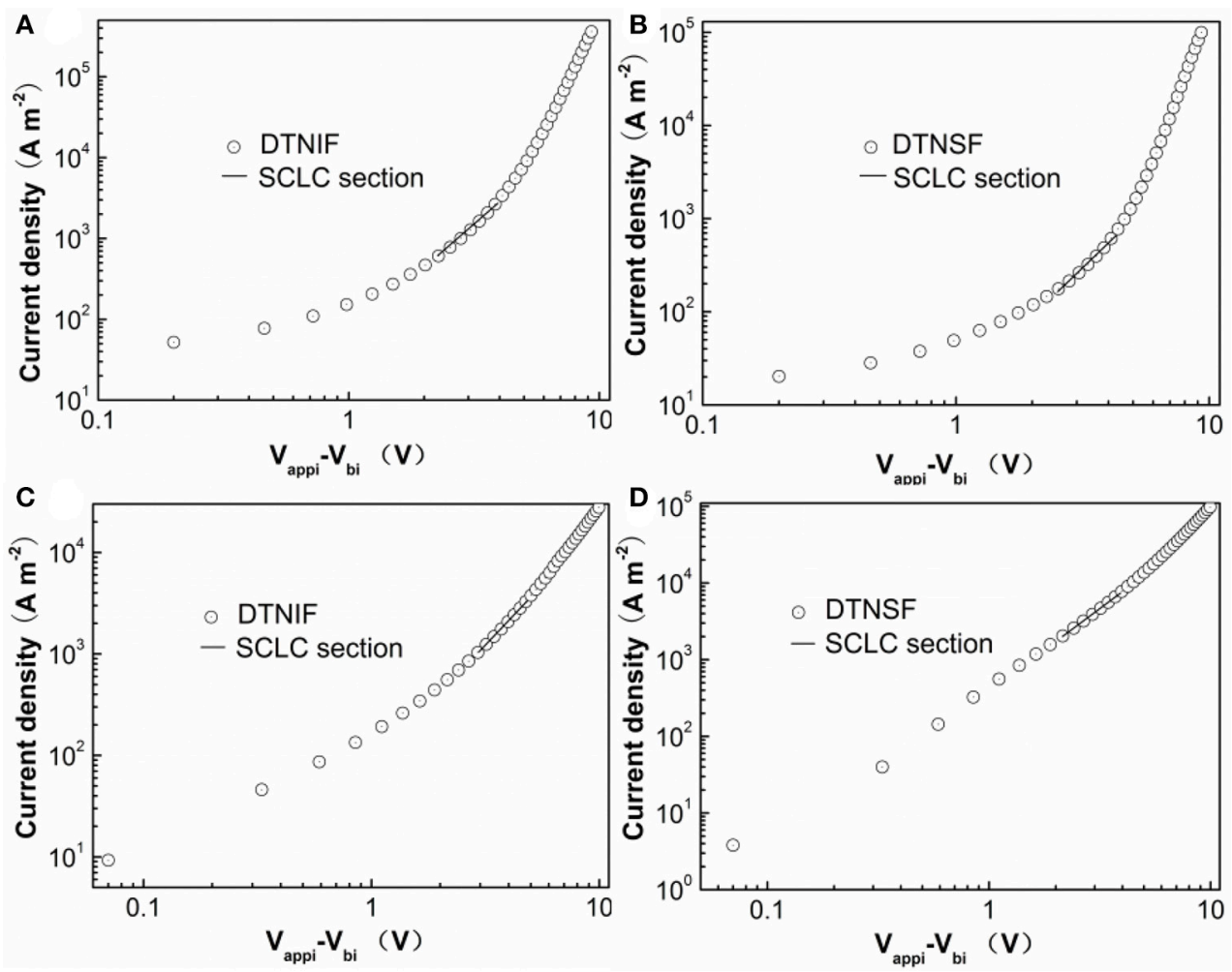

FIGURE $7 \mid J-V$ characteristic for (A,C) DTNIF and (B,D) DTNSF-based (A,B) electron-only and (C,D) hole-only devices.

TABLE 3 | Hole and electron mobilities of the SCLC devices based on two different active layers.

\begin{tabular}{lccc}
\hline Active layer & $\boldsymbol{\mu}_{\mathbf{e}}\left[\mathbf{c m}^{\mathbf{2}} \mathbf{~ V}^{\mathbf{1}} \mathbf{s}^{-\mathbf{1}}\right]$ & $\boldsymbol{\mu}_{\boldsymbol{h}}\left[\mathbf{c m}^{\mathbf{2}} \mathbf{V}^{-\mathbf{1}} \mathbf{s}^{-\mathbf{1}}\right]$ & $\boldsymbol{\mu}_{\boldsymbol{h}} / \boldsymbol{\mu}_{\boldsymbol{e}}$ \\
\hline PBDB-T:DTNIF & $1.79 \times 10^{-5}$ & $1.87 \times 10^{-5}$ & 1.04 \\
PBDB-T:DTNSF & $6.70 \times 10^{-6}$ & $1.35 \times 10^{-5}$ & 2.01 \\
\hline
\end{tabular}

OSCs might be improved by selecting other donor polymers of more complementary absorption spectra.

\section{EXPERIMENTAL SECTION}

\section{Materials and Characterization}

All the solvents were purified and dried according to standard procedures. The donor polymer PBDB-T (99.9\%) was bought from Solarmer Materials, Inc. Compounds $\mathbf{1}$ and $\mathbf{2}$ were prepared by using the reported procedure (Ma et al., 2013, 2017b).

Synthesis of 3: Compound 2 (0.6 g, $0.56 \mathrm{mmol})$, 5bromothiophene-2-carbaldehyde $(0.32 \mathrm{~g}, 1.6 \mathrm{mmol})$ and $\mathrm{Pd}\left(\mathrm{PPh}_{3}\right)_{4}(30 \mathrm{mg}, 0.03 \mathrm{mmol})$ were dissolved in $30 \mathrm{~mL}$ of degassed toluene in a two neck flask. After refluxing for $24 \mathrm{~h}$ under nitrogen, the mixture was cooled down to room temperature. Then the solvent was removed by evaporation, and the remaining residue was purified by column chromatography (silica gel) using petroleum ether/ $\mathrm{CH}_{2} \mathrm{Cl}_{2}(3: 1)$ as eluent. Finally, a dark brown solid $(0.47 \mathrm{~g}, 96 \%)$ was obtained. ${ }^{1} \mathrm{H} \mathrm{NMR}\left(\mathrm{CDCl}_{3}\right.$, $400 \mathrm{MHz}, \mathrm{ppm}): 9.91$ (s, 2H), 8.04 (d, $J=8.0 \mathrm{~Hz}, 2 \mathrm{H}), 7.75$ (d, $J=8.0 \mathrm{~Hz}, 2 \mathrm{H}), 7.67(\mathrm{~d}, J=8.0 \mathrm{~Hz}, 2 \mathrm{H}), 7.43(\mathrm{~s}, 2 \mathrm{H}), 7.37$ (s, 2H), 2.17-2.04 (m, 8H), 1.01-0.52 (m, 60H). HRMS (MALDI) $\mathrm{m} / \mathrm{z}$ : calc. for $\mathrm{C}_{62} \mathrm{H}_{80} \mathrm{O}_{2} \mathrm{~S}_{4}$ : 984.5017; found: 984.5027. Elemental analysis (\%) calc. for $\mathrm{C}_{62} \mathrm{H}_{80} \mathrm{O}_{2} \mathrm{~S}_{4}$ : $\mathrm{C}, 75.56 ; \mathrm{H}, 8.18$; found: $\mathrm{C}$, 75.79; H, 8.09.

Synthesis of DTNSF: To a solution of Compound 3 (200 mg, $0.2 \mathrm{mmol}$ ) in dry $\mathrm{CHCl}_{3}(30 \mathrm{~mL}), 2$-(6-fluoro-3-oxo-2,3-dihydro$1 \mathrm{H}$-inden-1-ylidene)malononitrile $(340 \mathrm{mg}, 1.6 \mathrm{mmol})$ were added. After degassing with nitrogen for $30 \mathrm{~min}, 0.15 \mathrm{~mL}$ of pyridine was added. The mixture was stirred at reflux for $24 \mathrm{~h}$ under nitrogen atmosphere. After the mixture was cooled to room temperature, it was poured into $100 \mathrm{~mL}$ of methanol. A precipitate was formed and filtered off which was further purified by using column chromatography (silica gel) with petroleum ether/ $\mathrm{CH}_{2} \mathrm{Cl}_{2}(1: 1)$ as the eluent. A dark green solid (130 mg, 46\%) was obtained. ${ }^{1} \mathrm{H} \mathrm{NMR}\left(\mathrm{CDCl}_{3}\right.$, $400 \mathrm{MHz}, \mathrm{ppm}): 8.91(\mathrm{~d}, J=8.0 \mathrm{~Hz}, 2 \mathrm{H}), 8.42(\mathrm{~d}, J=$ $8.0 \mathrm{~Hz}, 2 \mathrm{H}), 8.10(\mathrm{~d}, J=8.0 \mathrm{~Hz}, 2 \mathrm{H}), 8.01-7.97(\mathrm{~m}, 2 \mathrm{H})$, $7.86(\mathrm{~d}, J=8.0 \mathrm{~Hz}, 2 \mathrm{H}), 7.73-7.70(\mathrm{~m}, 2 \mathrm{H}), 7.68(\mathrm{~d}, J=$ $8.0 \mathrm{~Hz}, 2 \mathrm{H}), 7.50-7.45(\mathrm{~m}, 4 \mathrm{H}), 2.20-2.09(\mathrm{~m}, 8 \mathrm{H}), 1.05-0.54$ $(\mathrm{m}, 60 \mathrm{H})$. HRMS (MALDI) $\mathrm{m} / \mathrm{z}$ : calc. for $\mathrm{C}_{86} \mathrm{H}_{86} \mathrm{~F}_{2} \mathrm{~N}_{4} \mathrm{O}_{2} \mathrm{~S}_{4}$ : 1,373.5689; found: 1,373.5674. Elemental analysis (\%) calc. for $\mathrm{C}_{86} \mathrm{H}_{86} \mathrm{~F}_{2} \mathrm{~N}_{4} \mathrm{O}_{2} \mathrm{~S}_{4}$ : C, 75.18; $\mathrm{H}, 6.31 ; \mathrm{N}, 4.08$; found: C, 75.47; $\mathrm{H}$, $6.20 ; \mathrm{N}, 3.77$. 
Synthesis of DTNIF: To a solution of Compound 1 (174 mg, $0.2 \mathrm{mmol}$ ) in dry $\mathrm{CHCl}_{3}(30 \mathrm{~mL}), 2$-(6-fluoro-3-oxo-2,3-dihydro$1 \mathrm{H}$-inden-1-ylidene)malononitrile $(337 \mathrm{mg}, 1.6 \mathrm{mmol})$ were added. After degassing with nitrogen for $30 \mathrm{~min}, 1 \mathrm{~mL}$ of pyridine was added into the mixture which was further stirred at reflux for $24 \mathrm{~h}$ under nitrogen atmosphere. Then the mixture was cooled down to room temperature. The reaction mixture was poured into $100 \mathrm{~mL}$ of methanol. A precipitate was formed and filtered off which was further purified by using column chromatography (silica gel) with petroleum ether/ $\mathrm{CH}_{2} \mathrm{Cl}_{2}(1: 1)$ as the eluent. A dark metallic luster solid (126 mg, 60\%) was obtained. ${ }^{1} \mathrm{H}$ NMR $\left(\mathrm{CDCl}_{3}, 400 \mathrm{MHz}, \mathrm{ppm}\right): 9.07$ (d, $J=$ $8.0 \mathrm{~Hz}, 2 \mathrm{H}), 8.79-8.76(\mathrm{~m}, 0.8 \mathrm{H}), 8.46-8.43(\mathrm{~m}, 3.2 \mathrm{H}), 8.04-$ $8.00(\mathrm{~m}, 1.3 \mathrm{H}), 7.93-7.88(\mathrm{~m}, 2 \mathrm{H}), 7.85-7.80(\mathrm{~m}, 2 \mathrm{H}), 7.67-$ $7.64(\mathrm{~m}, 0.7 \mathrm{H}), 7.51-7.46(\mathrm{~m}, 2 \mathrm{H}), 2.23-2.11(\mathrm{~m}, 8 \mathrm{H}), 1.00-$ $0.52(\mathrm{~m}, 60 \mathrm{H})$. HRMS (MALDI) $\mathrm{m} / \mathrm{z}$ : calc. for $\mathrm{C}_{78} \mathrm{H}_{82} \mathrm{~F}_{2} \mathrm{~N}_{4} \mathrm{O}_{2} \mathrm{~S}_{2}$ : 1,209.5891; found: 1,209.5920. Elemental analysis (\%) calc. for $\mathrm{C}_{78} \mathrm{H}_{82} \mathrm{~F}_{2} \mathrm{~N}_{4} \mathrm{O}_{2} \mathrm{~S}_{2}$ : C, 77.45; H, 6.83; N, 4.63; found: C, 77.50; $\mathrm{H}$, $7.26 ; \mathrm{N}, 4.24$.

\section{OSC Fabrication and Characterization}

PSCs were fabricated by using a device configuration of indium tin oxide (ITO)/ZnO/active layer/ $/ \mathrm{MoO}_{3} / \mathrm{Ag}$. The ITO glass was cleaned by sequentially in detergent, deionized water, acetone, and isopropanol for half an hour each and dried for more than $12 \mathrm{~h}$ in an oven. Then, the ITO glass was subjected to ultraviolet/ozone treatment for $15 \mathrm{~min}$. Later on, a $\mathrm{ZnO}$ precursor solution $(0.23 \mathrm{M}$ in 2-methoxyethanol) was spincoated on the ITO glass at 3,000 rpm for $50 \mathrm{~s}$. On a hot plate $\left(130^{\circ} \mathrm{C}\right)$, the obtained films were heated for $10 \mathrm{~min}$ first, then they were annealed by an oven $\left(200^{\circ} \mathrm{C}\right)$ for $1 \mathrm{~h}$. The blend ratios of the active layer (PBDB-T:acceptor) were fixed at 1:1 by weight. The donor/acceptor blends were dissolved in chlorobenzene with a total concentration of $18 \mathrm{mg} / \mathrm{mL}$ and spin-coated on top of the $\mathrm{ZnO}$ film (ca. $30 \mathrm{~nm}$ ) in the glovebox. Finally, on the active layer, $10 \mathrm{~nm}$ of $\mathrm{MoO}_{3}$ film was deposited followed by a further deposition of $\mathrm{Ag}$ film $(100 \mathrm{~nm})$. The active area of OSC devices was $6 \mathrm{~mm}^{2}$.

Solar cell characterization was tested under AM $1.5 \mathrm{G}$ irradiation $\left(100 \mathrm{~mW} \mathrm{~cm} \mathrm{~cm}^{-2}\right)$ from an Oriel Sol3A simulator (Newport) with a NREL-certified silicon reference cell. $J-V$ measurements were carried out in air using a Keithley 2440 source measurement unit. External quantum efficiency (EQE) data were collected by a Newport EQE measuring system.

\section{Instruments and Measurements}

${ }^{1} \mathrm{H}$ NMR was measured in $\mathrm{CDCl}_{3}$ on a Bruker AVANCEspectrometer. Elemental analysis of the non-fullerene acceptors was obtained on an Elementar Vario EL Cube analyzer. UVVis absorption spectra for all the samples were performed on a Perkin-Elmer Lambda 365 spectrophotometer. Linear emission spectra for pure films or blended films were obtained by using a FLS920 spectrophotometer. Atomic force microscopy (AFM) was conducted in a tapping mode with a Bruker Nanoscale
V station. A Bruker Dektak XT surface profilometer was used to test the thickness of thin films in this work. A threeelectrode $\mathrm{CHI}$ 604E electrochemical workstation was used to run the cyclic voltammetry $(\mathrm{CV})$ using $\mathrm{Bu}_{4} \mathrm{NPF}_{6}$ solution $\left(0.1 \mathrm{M}\right.$ in acetonitrile) and a scan rate of $100 \mathrm{mV} \mathrm{s}^{-1}$. The solid films were precipitated on a Pt plate through dipping the Pt plate into the corresponding chloroform solutions and then took out for drying. $\mathrm{Ag} / \mathrm{AgNO}_{3}$ and a $\mathrm{Pt}$ wire were chosen as the reference electrode and the counter electrode, respectively. The LUMO and HOMO energy levels of films made by the small molecule were calculated by using the following equations:

$$
\begin{gathered}
E_{\mathrm{HOMO}}=-\left(\varphi_{\mathrm{ox}}+4.82\right)(\mathrm{eV}) \\
E_{\mathrm{LUMO}}=-\left(\varphi_{\mathrm{RED}}+4.82\right)(\mathrm{eV})
\end{gathered}
$$

Agilent 4155C semiconductor parameter analyzer was used to conduct the mobility measurements. Electron and hole mobilities were determined by using the space charge limited current model (SCLC) with an electron-only diode configuration of ITO/ZnO/active layer/Ca/Al and an hole-only diode configuration of ITO/PEDOT:PSS/active layer/Au, using current-voltage measurements in the range of -(3-10) $\mathrm{V}$ in the dark. The SCLC mobility was calculated by fitting the $J$ - $V$ curves to the Mott-Gurney relationship:

$$
J=\frac{9}{8} \varepsilon_{r} \varepsilon_{0} \mu \frac{V^{2}}{L^{3}}
$$

Where $\varepsilon_{0}$ is the permittivity of free space $\left(8.85 \times 10^{-12} \mathrm{~F} \mathrm{~m}^{-1}\right)$, $\varepsilon_{\mathrm{r}}$ is the dielectric constant of the active layer material (assumed to be 3$), \mu$ is the electron or hole mobility, $L$ is the active layer thickness, $V$ is the voltage drop across the electronor hole-only device $\left(V_{\text {appl }}-V_{\text {bi }}\right.$, where $V_{\text {appl }}$ is the applied voltage, and $V_{\mathrm{bi}}$ is the built-in voltage induced by the work function difference of the two electrodes). The electron/hole mobilities can be determined according to the slope of the $J^{1 / 2}-V$ curves.

\section{AUTHOR CONTRIBUTIONS}

QZ conceived the experiments. MZ and YM were primarily responsible for the experiments. $\mathrm{MZ}$ and $\mathrm{QZ}$ wrote the manuscript. All authors discussed the results.

\section{FUNDING}

This work was supported by the National Natural Science Foundation of China (Nos. U1605241, 51703226, 51561165011), the Key Research Program of Frontier Sciences, CAS (No. QYZDB-SSW-SLH032), the CAS/SAFEA International Partnership Program for Creative Research Teams, and the Strategic Priority Research Program of the Chinese Academy of Sciences, Grant No. XDB20000000. 


\section{REFERENCES}

Chen, J. D., Cui, C., Li, Y. Q., Zhou, L., Ou, Q. D., Li, C., et al. (2015). Polymer solar cells: single-junction polymer solar cells exceeding $10 \%$ power conversion efficiency. Adv. Mater. Weinheim. 27, 1035-1041. doi: 10.1002/adma.201404535

Chen, Y., Wan, X., and Long, G. (2013). High performance photovoltaic applications using solution-processed small molecules. Acc. Chem. Res. 46, 2645-2655. doi: 10.1021/ar400088c

Dai, S., Zhao, F., Zhang, Q., Lau, T. K., Li, T., Liu, K., et al. (2017). Fused nonacyclic electron acceptors for efficient polymer solar cells. J. Am. Chem. Soc. 139, 1336-1343. doi: 10.1021/jacs.6b12755

Elumalai, N. K., and Uddin, A. (2016). Open circuit voltage of organic solar cells: an in-depth review. Energy Environ. Sci. 9, 391-410. doi: 10.1039/c5ee02871j

Facchetti, A. (2011). $\pi$-Conjugated polymers for organic electronics and photovoltaic cell applications. Chem. Mater. 23, 733-758. doi: $10.1021 / \mathrm{cm} 102419 \mathrm{z}$

He, Z., Xiao, B., Liu, F., Wu, H., Yang, Y., Xiao, S., et al. (2015). Single-junction polymer solar cells with high efficiency and photovoltage. Nat. Photonics 9, 174-179. doi: 10.1038/nphoton.2015.6

Li, H., Earmme, T., Subramaniyan, S., and Jenekhe, S. A. (2015). Bis(Naphthalene Imide)diphenylanthrazolines: a new class of electron acceptors for efficient nonfullerene organic solar cells and applicable to multiple donor polymers. Adv. Energy Mater. 5:1402041. doi: 10.1002/aenm.201402041

Lin, Y., Wang, J., Zhang, Z. G., Bai, H., Li, Y., Zhu, D., et al. (2015). An electron acceptor challenging fullerenes for efficient polymer solar cells. Adv. Mater. 27, 1170-1174. doi: 10.1002/adma.201404317

Liu, F., Zhou, Z., Zhang, C., Vergote, T., Fan, H., Liu, F., et al. (2016). A thieno[3,4b] thiophene-based non-fullerene electron acceptor for high-performance bulkheterojunction organic solar cells. J. Am. Chem. Soc. 138, 15523-15526. doi: $10.1021 /$ jacs.6b08523

Liu, W., Li, W., Yao, J., and Zhan, C. (2018). Achieving high shortcircuit current and fill-factor via increasing quinoidal character on nonfullerene small molecule acceptor. Chin. Chem. Lett. 29, 381-384. doi: 10.1016/j.cclet.2017.11.018

Liu, Y., Zhao, J., Li, Z., Mu, C., Ma, W., Hu, H., et al. (2014). Aggregation and morphology control enables multiple cases of high-efficiency polymer solar cells. Nat. Commun. 5:5293. doi: 10.1038/ncomms6293

Ma, Y., Kang, Z., and Zheng, Q. (2016). Recent advances in wide bandgap semiconducting polymers for polymer solar cells. J. Mater. Chem. A 5, 1860-1872. doi: 10.1039/c6ta09325f

Ma, Y., Zhang, M., Tang, Y., Ma, W., and Zheng, Q. (2017a). Angular-Shaped dithienonaphthalene-based non-fullerene acceptor for high-performance polymer solar cells with large open-circuit voltages and minimal energy losses. Chem. Mater. 22, 9775-9785. doi: 10.1021/acs.chemmater.7b03770

Ma, Y., Zhang, M., Yu, Y., Xin, J., Wang, T., Ma, W., et al. (2017b). Ladder-type dithienonaphthalene-based small-molecule acceptors for efficient nonfullerene organic solar cells. Chem. Mater. 29, 7942-7952. doi: 10.1021/acs.chemmater.7b02887

Ma, Y., Zheng, Q., Yin, Z., Cai, D., Chen, S. C., and Tang, C. (2013). Ladder-type dithienonaphthalene-based donor-acceptor copolymers for organic solar cells. Macromolecules 46, 4813-4821. doi: 10.1021/ma400696e

Nielsen, C. B., Holliday, S., Chen, H. Y., Cryer, S. J., and Mcculloch, I. (2015). Non-fullerene electron acceptors for use in organic solar cells. Acc. Chem. Res. 48, 2803-2812. doi: 10.1021/acs.accounts.5b 00199
Qin, Y., Uddin, M. A., Chen, Y., Jang, B., Zhao, K., Zheng, Z., et al. (2016). Highly efficient fullerene-free polymer solar cells fabricated with polythiophene derivative. Adv. Mater. 28, 9416-9422. doi: 10.1002/adma.2016 01803

Rong, Z., Deng, Y., Xie, Z., Geng, Y., and Wang, F. (2015). Dithienocarbazoleand benzothiadiazole-based donor-acceptor conjugated polymers for bulk heterojunction polymer solar cells. Sci. China Chem. 58, 294-300. doi: 10.1007/s11426-014-5221-9

Shen, F., Xu, J., Li, X., and Zhan, C. (2018). Nonfullerene small-molecule acceptors with perpendicular side-chains for fullerene-free solar cells. J. Mater. Chem. A 6, 15433-15455. doi: 10.1039/C8TA04718A

Tang, C., Chen, S. C., Shang, Q., and Zheng, Q. (2017). Asymmetric indenothiophene-based non-fullerene acceptors for efficient polymer solar cells. Sci. China Mater. 60, 707-715. doi: 10.1007/s40843-0179059-3

Wang, E., Mammo, W., and Andersson, M. R. (2014). 25th anniversary article: isoindigo-based polymers and small molecules for bulk heterojunction solar cells and field effect transistors. Adv. Mater. 26, 1801-1826. doi: 10.1002/adma.201302652

Wu, J. L., Chen, F. C., Hsiao, Y. S., Chien, F. C., Chen, P., Kuo, C. H., et al. (2011). Surface plasmonic effects of metallic nanoparticles on the performance of polymer bulk heterojunction solar cells. ACS Nano 5, 959-967. doi: $10.1021 / \mathrm{nn} 102295 \mathrm{p}$

Wu, J. S., Cheng, S. W., Cheng, Y. J., and Hsu, C. S. (2015). Donor-acceptor conjugated polymers based on multifused ladder-type arenes for organic solar cells. Chem. Soc. Rev. 44, 1113-1154. doi: 10.1039/c4cs00250d

Xu, X., Wang, C., Bäcke, O., James, D. I., Bini, K., Olsson, E., et al. (2015). Pyrrolo[3,4-g]quinoxaline-6,8-dione-based conjugated copolymers for bulk heterojunction solar cells with high photovoltages. Polym. Chem. 6, 4624-4633. doi: 10.1039/c5py00394f

You, J., Dou, L., Yoshimura, K., Kato, T., Ohya, K., Moriarty, T., et al. (2013). A polymer tandem solar cell with $10.6 \%$ power conversion efficiency. Nat. Commun. 4:1446. doi: 10.1038/ncomms2411

Zhan, X., Facchetti, A., Barlow, S., Marks, T. J., Ratner, M. A., Wasielewski, M. R., et al. (2011). Rylene and related diimides for organic electronics. Adv. Mater. 23, 268-284. doi: 10.1002/adma.201001402

Zhang, S., Ye, L., Zhao, W., Yang, B., Wang, Q., and Hou, J. (2015). Realizing over $10 \%$ efficiency in polymer solar cell by device optimization. Sci. China Chem. 58, 248-256. doi: 10.1007/s11426-014-5273-x

Zhang, X., Yao, J., and Zhan, C. (2016). Synthesis and photovoltaic properties of low bandgap dimeric perylene diimide based non-fullerene acceptors. Sci. China Chem. 59, 209-217. doi: 10.1007/s11426-015-5485-8

Zhao, F., Dai, S., Wu, Y., Zhang, Q., Wang, J., Jiang, L., et al. (2017). Singlejunction binary-blend nonfullerene polymer solar cells with $12.1 \%$ efficiency. Adv. Mater. 29, 1604059. doi: 10.1002/adma.201700144

Conflict of Interest Statement: The authors declare that the research was conducted in the absence of any commercial or financial relationships that could be construed as a potential conflict of interest.

Copyright $\odot 2018$ Zhang, Ma and Zheng. This is an open-access article distributed under the terms of the Creative Commons Attribution License (CC BY). The use, distribution or reproduction in other forums is permitted, provided the original author(s) and the copyright owner(s) are credited and that the original publication in this journal is cited, in accordance with accepted academic practice. No use, distribution or reproduction is permitted which does not comply with these terms. 